\title{
ẢNH HUOỎNG CỦA MẬT ĐỘ NUÔI LÊN TỐC ĐỘ TĂNG TRƯỎNG VÀ TỶ LỆ SỐNG CỦA CÁ ÔNG TIÊN (PTEROPHYLLUM ALTUM PELLEGRIN, 1930)
}

\author{
Hà Lê Thị Lộc ${ }^{1 *}$, Nguyễn Thị Mỹ Dung ${ }^{2}$ \\ ${ }^{1}$ Viện Hải dương học-Viện Hàn lâm Khoa học và Công nghệ Việt Nam \\ ${ }^{2}$ Trường Đại học Nha Trang \\ "Email: haleloc@yahoo.com
}

Ngày nhận bài: 7-2-2014

\begin{abstract}
TÓM TÄT: Cá ông tiên (Pterophyllum altum) sau 3 ngày nở được nuôi trong các bể kính có thể tích 25 lít với các mât độ 5 con/lít, 10 con/lít, 15 con/lít và 20 con/lít (3 lần lặp lại) để làm rõ ảnh huởng của mật độ đến tốc độ tăng trưởng và tỷ lệ sống của cá. Kết quả sau 84 ngày thí nghiệm cho thấy có sư ảnh huởng của mật độ nuôi đến tốc độ tăng truởng và tỷ lệ sống của cá giai đoạn 3 tháng đầu mới nở Cá được nuôi ở mật độ 5 con/lít có tốc độ tăng trưởng về chiều dài và trọng luợng $(9,597 \pm 0,002 \mathrm{~mm} ; 11,700 \pm 0, \dot{1} \mathrm{~g})$ là tốt nhất và khác nhau đáng kể so với cá được nuôi ở mật độ 10 con/lit $(9,167 \pm 0,058 \mathrm{~mm} ; 11,067 \pm 0,208 \mathrm{~g}) 15 \mathrm{con} / \mathrm{lit}(7,699 \pm 0,03 \mathrm{~mm} ; 10,933 \pm 0,057 \mathrm{~g})$ và 20 con/lít $(4,928 \pm 0,004 \mathrm{~mm} ; 7,900 \pm 0,1 \mathrm{~g})(P<0,05)$. Tỷ lẹ sống của cá nuôi ở mật độ 5 con/lít là

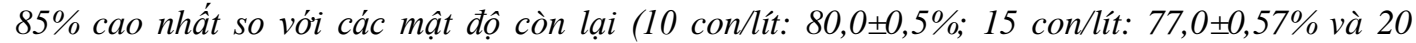
con/lit: $74,6 \pm 0,38 \%)$. Kết quả thí nghiệm cho thấy cá ông tiên mới nở đến 3 tháng tuổi nên nuôi ở mật độ 5 con/lít là tốt nhất.
\end{abstract}

Tù khóa: Mật độ nuôi, tốc độ tăng trưởng, tỷ lệ sống, cá ông tiên.

\section{MỞ ĐẦU}

Xuất hiện trong thế giới cá cảnh từ đầu thế kỷ $X X$, cá ông tiên là một trong những loài cá cảnh nước ngọt được ưa chuộng nhất, trước đây cá ông tiên thuộc hàng quý hiếm bậc nhất trong danh sách cá cảnh thế giới, do khó thuần dưỡng nên nguồn cung cấp chủ yếu dựa vào khai thác tự nhiên. Chúng có nguồn gốc từ $\mathrm{Ai}$ Cập và từ sông Amazon của Nam Phi.

Cá ông tiên được nhập vào Việt Nam khoảng nửa thế kỷ nay. Theo kết quả khảo sát trong năm 2008, trên thị trường thành phố Hồ Chí Minh có khoảng 21 kiểu hình rất hiếm như: hắc phù mị, bố lí, cá thần tiên Ai Cập, albino... [3], chúng có giá trị nhờ vào màu sắc và khó lai tạo. Trên thị trường chúng được bán với giá 5 USD - 20 USD đối với cá giống và 10 USD -
40 USD đối với cá trưởng thành. Cá ông tiên vừa đẹp về màu sắc và hấp dẫn về hình dáng, là một loại cá có tập tính hiền lành, nhút nhát, có khả năng sinh sản trong điều kiện nuôi nhốt. Chúng có thể nuôi chung được với cá tàu, cá hồng kim và nhiều loại cá cảnh khác [3].

Tuy nhiên cho đến nay, ở Việt Nam chưa có một công trình nào nghiên cứu về loài cá này đã được công bố. Bài báo này là một phần Luận án Thạc sĩ Nông nghiệp của Nguyễn Thị Mỹ Dung đã được thực hiện từ năm 2012 đến 2013, kêt quả đạt được là cơ sở cho những nghiên cứu tiếp theo về sản xuất giống đối tượng này trong tương lai.

\section{PHƯƠNG PHÁP NGHIÊN CÚU}

Thời gian nghiên cúu: Nghiên cứu đã được thực hiện từ tháng 6/2012 đển 6/2013. 
Đối tựng nghiên cứu: loài cá ông tiên (Pterophyllum altum Pellegrin, 1930) [4].

Địa điểm nghiên cứu: Cá bố mẹ đang được nuôi tại phòng thí nghiệm thuộc phòng Công nghệ Nuôi trồng thuộc Viện Hải dương học.

Nguồn cá thí nghiệm: Cá được chọn từ cùng một đợt đẻ của một cặp cá bố mê, sau khi nở 3 ngày tuổi, noãn hoàng tiêu biến, cá bắt đầu ăn thức ăn ngoài thì chuyển sang các bể làm thí nghiệm.

Bố trí thí nghiệm: Thí nghiệm về ảnh hưởng của mật độ thả ban đầu được thực hiện với 4 nghiệm thức khác nhau về mật độ. Thời gian thí nghiệm 3 tháng. Mỗi nghiệm thức 3 lần lặp lại, gồm 12 lô thí nghiệm. Thể tích mỗi bể là 25 lít.

Mật độ cá trong các nghiệm thức được phân bố như sau:

Nghiệm thức 1: mật độ nuôi 5 con/lít;

Nghiệm thức 2: mật độ nuôi 10 con/lít;

Nghiêm thức 3: mật độ nuôi 15 con/lít;

Nghiệm thức 4: mật độ nuôi 20 con /lít

Theo dõi diễn biến của tỷ lệ sống và tốc độ tăng trưởng của cá trong các nghiệm thức.

\section{Quá trình chăm sóc cá:}

Thức ăn: Cá con mới nở được cho ăn bằng thức ăn tươi sống gồm: nauplius của artermia mật độ $5-7$ cá thể/ml và tăng dần $7-10$ cá thể/ml cho đến khi cá được 15 ngày tuổi thì chuyển qua cho ăn trùn chỉ đến 90 ngày tuổi. Tất cả các lô thí nghiệm được chăm sóc như nhau, hàng ngày cá được cho ăn 2 lần vào lúc 8 giờ sáng và 2 giờ chiều.

Thay nước: 50\% lượng nước mới/ngày.

Môi trường: các yếu tố môi trường được theo dõi hàng ngày và duy trì ổn định trong suốt quá trình thí nghiệm.

\section{Phương pháp thu thập và xử lý số liệu}

Các thông số môi truòng trong hệ thống thí nghiệm

Các yếu tố môi trường trong các bể nuôi được đo đạc hàng ngày vào lúc 9 giờ sáng và 3 giờ chiều.
Nhiệt độ: đo bằng nhiệt kế thủy ngân;

$\mathrm{pH}$ : đo bằng test $\mathrm{pH}$;

Oxy hòa $\tan (\mathrm{DO})$ : đo bằng test oxy.

Xác định các thông số và công thức tính

Các lô thí nghiệm được kiểm tra và quan sát tình trạng sức khỏe cá hàng ngày. Định kỳ cân, đo cá 7 ngày/ lần, xác định tỷ lệ sống, tăng trưởng chiều dài toàn thân, chiều cao thân $(\mathrm{Lt}, \mathrm{mm})$ và khối lượng toàn thân $(\mathrm{Wt}, \mathrm{g})$ của các lô cá thí nghiệm.

Tốc độ tăng trưởng đặc trưng về chiều dài toàn thân $\left(\mathrm{SGR}_{\mathrm{L}}\right)$ được tính theo công thức:

$$
S G R_{L}=\frac{L n L_{2}-L n L_{1}}{t_{2}-t_{1}} \times 100
$$

Trong đó:

$\mathrm{SRG}_{\mathrm{L}}$ : tốc độ tăng trưởng đặc trưng về chiều dài toàn thân (\%/ngày);

$\mathrm{L}_{1}$ : chiều dài cá ở thời điểm $\mathrm{t}_{1}(\mathrm{~mm})$;

$\mathrm{L}_{2}$ : chiều dài cá ở thời điểm $\mathrm{t}_{2}(\mathrm{~mm})$; $1 \mathrm{~mm}$;

Cá được đo bằng thước có độ chính xác

Tốc độ tăng trưởng khối lượng đặc trưng:

$$
S G R_{\mathrm{W}}=\frac{L n \mathrm{~W}_{2}-\operatorname{Ln} \mathrm{W}_{1}}{t_{2}-t_{1}} \times 100
$$

Mức tăng chiều dài tuyệt đối

$$
\mathrm{GR}_{\mathrm{L}}=\mathrm{L}_{2}-\mathrm{L}_{1}(\mathrm{~mm})
$$

Mức tăng khối lượng tuyệt đối

$$
\mathrm{GR}_{\mathrm{L}}=\mathrm{W}_{2^{-}}-\mathrm{W}_{1}(\mathrm{~g})
$$

Xác định tỷ lệ sống của cá thức:

Tỷ lệ sống $\mathrm{T}$ (\%) được tính theo công

$$
T=\frac{N_{s}}{N_{t}} \times 100(\%)
$$

Trong đó:

$\mathrm{N}_{\mathrm{s}}$ : Số lượng cá tại thời điểm hiện tại;

$\mathrm{N}_{\mathrm{t}}$ : Số lượng cá tại thời điểm trước đã được xác định. 
Phân tích số liệu

Số liệu được xử lý với bảng tính Excel và chương trình SPSS 15.0 với ANOVA một yếu tố để so sánh độ sai khác có ý nghĩa thống kê giữa các nghiệm thức ở mức $\mathrm{P}<0,05$.

\section{KẾT QUẢ NGHIÊN CÚ̉U}

Một số yếu tố môi trường ở các nghiệm thức trong quá trình thí nghiệm
Nhiệt độ: Trong đợt thí nghiệm, ở cả 4 nghiệm thức không có sự khác biệt về nhiệt độ, dao động trong khoảng từ $24-28{ }^{0} \mathrm{C}$. Do nuôi trong bể trong phòng thí nghiệm nên nhiệt độ môi trường nuôi ổn định và biên độ dao động trong ngày không quá lớn. Nhiệt độ thích hợp của cá ông tiên là $26-30{ }^{\circ} \mathrm{C}$. Như vậy nhiệt độ trong quá trình thí nghiệm khá phù hợp với sự sinh trưởng và phát triển của cá ông tiên [2].

Bảng 1. Diễn biến các yếu tố môi trường ở các nghiệm thức

\begin{tabular}{|c|c|c|c|c|c|}
\hline \multirow{2}{*}{\multicolumn{2}{|c|}{ Yếu tố môi trường }} & \multicolumn{4}{|c|}{ Các nghiệm thức } \\
\hline & & \multirow{2}{*}{$\frac{5 \text { con/lít }}{24,3 \div 27,1}$} & \multirow{2}{*}{$\frac{10 \text { con/lít }}{24,4 \div 27,5}$} & \multirow{2}{*}{$\frac{15 \text { con/lít }}{24,7 \div 27,8}$} & \multirow{2}{*}{$\frac{20 \text { con/lít }}{24,3 \div 27,4}$} \\
\hline Nhiôtđtô $0^{0} \mathrm{C}$ & Dao động & & & & \\
\hline ) & Trung bình & $25,8 \pm 0,8$ & $25,8 \pm 0,8$ & $25,4 \pm 1,0$ & $25,9 \pm 0,7$ \\
\hline \multirow{2}{*}{$\begin{array}{l}\text { Oxy hòa tan } \\
\text { (mg/lít) }\end{array}$} & Dao động & $3,75 \div 4,93$ & $3,56 \div 4,84$ & $3,27 \div 4,59$ & $3,26 \div 4,73$ \\
\hline & Trung bình & $4,18 \pm 0,48$ & $4,17 \pm 0,46$ & $4,11 \pm 0,42$ & $4,11 \pm 0,44$ \\
\hline $\mathrm{pH}$ & Dao động & $6,4 \div 7,2$ & $6,2 \div 7,4$ & $6,2 \div 7,6$ & $6,3 \div 7,8$ \\
\hline
\end{tabular}

Oxy hòa tan: Các lô thí nghiệm được bố trí sục khí 24/24 nên lượng oxy hòa tan đảm bảo cho sự sống của cá ông tiên.

pH: Ở sinh cảnh tự nhiên, cá ông tiên sinh sống ở các sông suối, nơi có giá trị pH từ 6,5 7,0 khoảng $\mathrm{pH}$ được xem là tối ưu loài [3]. Song, cho đến nay tác động của độ $\mathrm{pH}$ tới sự sinh trưởng và sinh sản vẫn chưa được nghiên cứu cụ thể.

\section{Ảnh hưởng của mật độ đến tăng trưởng của cá ông tiên}

Tăng trưởng về chiều dài toàn thân và khối lượng toàn thân cá ông tiên được định kỳ đo đạt và được thống kê ở bảng 2 .

Từ ngày nuôi 1 đến ngày thứ 35 không có sự khác biệt về chiều dài giữa các nghiệm thức 1 , nghiệm thức 2 , nghiệm thức $3(\mathrm{p}>0,05)$, giai đoạn này cá ông tiên tăng trưởng chậm, từ ngày thứ 35 đến ngày thứ 84 , giai đoạn tiền trưởng thành, cá ông tiên tăng trưởng nhanh và có sự khác biệt rõ rệt. Nghiệm thức 1 và 4 có sự khác biệt so với tất cả các nghiệm thức $(\mathrm{p}<0,05)$, giữa nghiệm thức 2 và nghiệm thức 3 không có sự khác biệt $(\mathrm{p}>0,05)$.
Sự tăng trưởng của cá ông tiên nhanh nhất ở nghiệm thức 1 và chiều dài trung bình $9,597 \pm 0,002 \mathrm{~cm}$, khối lượng trung bình là $11,7 \pm 0,1 \mathrm{~g}$ sau 84 ngày nuôi, nghiệm thức 2 là $9,167 \pm 0,058 \mathrm{~cm}$ và $11,067 \pm 0,208 \mathrm{~g}$, nhưng ở nghiệm thức 3 sau 84 ngày nuôi chỉ đạt $7,699 \pm 0,030 \mathrm{~cm}$, khối lượng trung bình $10,933 \pm 0,057 \mathrm{~g}$ và nghiệm thức 4 chiều dài

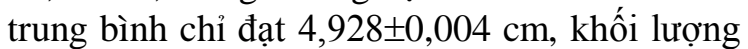
trung bình đạt $7,900 \pm 0,100 \mathrm{~g}$. Kết quả nghiên cứu cho thấy mật độ thả cá 5 con/lít sau 84 ngày nuôi cá tăng kích thước và khối lượng nhanh nhất và giảm dần ở các nghiệm thức 10 con/lít, 15 con/lít, 20 con/lít. Điều đó cho thấy khi mật độ quần thể cá ông tiên tăng cao sẽ gây ra sự cạnh tranh thức ăn, không gian sống, tiêu hao oxy đã dẫn đến cá sinh trưởng chậm ở các nghiệm thức này.

Tương tự, tốc độ tăng trưởng của lô thí nghiệm 1 và 2 cao hơn so với nghiệm thức 3 và 4 , có sự sai khác về mặt thống kê $(\mathrm{p}<0,05)$. Sau 84 ngày tuổi, tốc độ tăng trưởng của nghiệm thức 1 là $3,8 \pm 0,000$, nghiệm thức 2 là $3,8 \pm 0,001$ cao hơn so với nghiệm thức 3 là $2,1 \pm 0,002$ và nghiệm thức 4 là $1,8 \pm 0,000$. 
Ảnh hưởng của mật độ nuôi lên tốc độ ...

Bảng 2. Sự tăng trưởng chiều dài toàn thân và khối lượng toàn thân của cá ông tiên $(\mathrm{cm})$ trong thời gian nghiên cứu

\begin{tabular}{|c|c|c|c|c|c|}
\hline \multirow{2}{*}{$\begin{array}{l}\text { Các chỉ } \\
\text { tiêu }\end{array}$} & \multirow{2}{*}{$\begin{array}{l}\text { Ngày thí } \\
\text { nghiệm }\end{array}$} & \multicolumn{4}{|c|}{ Nghiệm thức } \\
\hline & & 5 con/lít (1) & 10 con/lít (2) & 15 con/lít (3) & 20 con/lít (4) \\
\hline \multirow{17}{*}{$\begin{array}{l}\text { Chiều dài } \\
\text { toàn thân } \\
\text { Lt }(\mathrm{cm})\end{array}$} & 1 & $0,264 \pm 0,000^{\mathrm{a}}$ & $0,264 \pm 0,000^{a}$ & $0,264 \pm 0,000^{a}$ & $0,264 \pm 0,000$ \\
\hline & 7 & $0,620 \pm 0,000^{\mathrm{a}}$ & $0,615 \pm 0,004^{a}$ & $0,620 \pm 0,000^{a}$ & $0,608 \pm 0,007^{a}$ \\
\hline & 14 & $0,849 \pm 0,022^{a}$ & $0,821 \pm 0,018^{a}$ & $0,821 \pm 0,018^{a}$ & $0,784 \pm 0,010^{a}$ \\
\hline & 21 & $1,060 \pm 0,041^{a}$ & $1,059 \pm 0,042^{\mathrm{ab}}$ & $1,005 \pm 0,004^{\mathrm{ab}}$ & $1,010 \pm 0,006^{b}$ \\
\hline & 28 & $1,419 \pm 0,009^{a}$ & $1,311 \pm 0,004^{\mathrm{ab}}$ & $1,225 \pm 0,060^{\mathrm{ab}}$ & $1,300 \pm 0,084^{b}$ \\
\hline & 35 & $1,806 \pm 0,027^{a}$ & $1,680 \pm 0,017^{a}$ & $1,613 \pm 0,000^{\mathrm{a}}$ & $1,500 \pm 0,000^{\mathrm{a}}$ \\
\hline & 42 & $2,264 \pm 0,000^{a}$ & $2,161 \pm 0,003^{a b}$ & $2,127 \pm 0,060^{b}$ & $2,051 \pm 0,000^{c}$ \\
\hline & 49 & $2,846 \pm 0,000^{\mathrm{a}}$ & $2,737 \pm 0,010^{b}$ & $2,67 \pm 0,064^{b}$ & $2,237 \pm 0,000^{c}$ \\
\hline & 56 & $3,548 \pm 0,000^{a}$ & $3,436 \pm 0,005^{\mathrm{ab}}$ & $3,390 \pm 0,051^{b}$ & $2,853 \pm 0,034^{c}$ \\
\hline & 63 & $4,217 \pm 0,001^{a}$ & $4,117 \pm 0,002^{b}$ & $4,110 \pm 0,006^{b}$ & $3,221 \pm 0,008^{c}$ \\
\hline & 70 & $5,605 \pm 0,005^{\mathrm{a}}$ & $5,304 \pm 0,002^{b}$ & $5,310 \pm 0,008^{b}$ & $3,732 \pm 0,009^{c}$ \\
\hline & 77 & $7,352 \pm 0,004^{a}$ & $7,028 \pm 0,003^{b}$ & $6,661 \pm 0,112^{c}$ & $3,732 \pm 0,009^{d}$ \\
\hline & 84 & $9,597 \pm 0,002^{\mathrm{a}}$ & $9,167 \pm 0,058^{b}$ & $7,699 \pm 0,030^{c}$ & $4,9288 \pm 0,004^{d}$ \\
\hline & 1 & $0,010 \pm 0,000$ & $0,010 \pm 0,000$ & $0,010 \pm 0,000$ & $0,010 \pm 0,000$ \\
\hline & 7 & $0,037 \pm 0,005$ & $0,040 \pm 0,000$ & $0,040 \pm 0,000$ & $0,037 \pm 0,005$ \\
\hline & 14 & $0,057 \pm 0,005$ & $0,057 \pm 0,005$ & $0,057 \pm 0,005$ & $0,050 \pm 0,010$ \\
\hline & 21 & $0,467 \pm 0,028$ & $0,450 \pm 0,000$ & $0,450 \pm 0,000$ & $0,467 \pm 0,289$ \\
\hline \multirow{9}{*}{$\begin{array}{l}\text { Khối lượng } \\
\text { toàn thân } \\
\text { Wt }(\mathrm{g})\end{array}$} & 28 & $0,777 \pm 0,068$ & $0,800 \pm 0,062$ & $0,770 \pm 0,087$ & $0,763 \pm 0,040$ \\
\hline & 35 & $1,163 \pm 0,015$ & $1,163 \pm 0,005$ & $1,160 \pm 0,014$ & $1,130 \pm 0,010$ \\
\hline & 42 & $2,100 \pm 0,010$ & $2,097 \pm 0,015$ & $2,093 \pm 0,005$ & $2,017 \pm 0,057$ \\
\hline & 49 & $3,037 \pm 0,011$ & $3,033 \pm 0,015$ & $3,027 \pm 0,005$ & $2,833 \pm 0,057$ \\
\hline & 56 & $4,167 \pm 0,057$ & $4,167 \pm 0,057$ & $4,100 \pm 0,100$ & $3,400 \pm 0,100$ \\
\hline & 63 & $6,517 \pm 0,090$ & $6,367 \pm 0,051$ & $6,353 \pm 0,037$ & $4,167 \pm 0,057$ \\
\hline & 70 & $9,067 \pm 0,152$ & $8,843 \pm 0,037$ & $8,790 \pm 0,085$ & $5,467 \pm 0,152$ \\
\hline & 77 & $10,533 \pm 0,208$ & $10,000 \pm 0,100$ & $9,900 \pm 0,100$ & $6,733 \pm 0,208$ \\
\hline & 84 & $11,700 \pm 0,100$ & $11,067 \pm 0,208$ & $10,933 \pm 0,057$ & $7,900 \pm 0,100$ \\
\hline
\end{tabular}

Ghi chú: Các giá trị trên cùng 1 hàng có các chũ cái giống nhau biểu thị sự khác biệt không có ý nghĩa thống kê $(P>0,05)$.

Bảng 3. Tốc độ tăng trưởng đặc trưng $\left(\mathrm{SGR}_{\mathrm{L}}\right)$ về chiều dài cá ông tiên ở các mật độ khác nhau

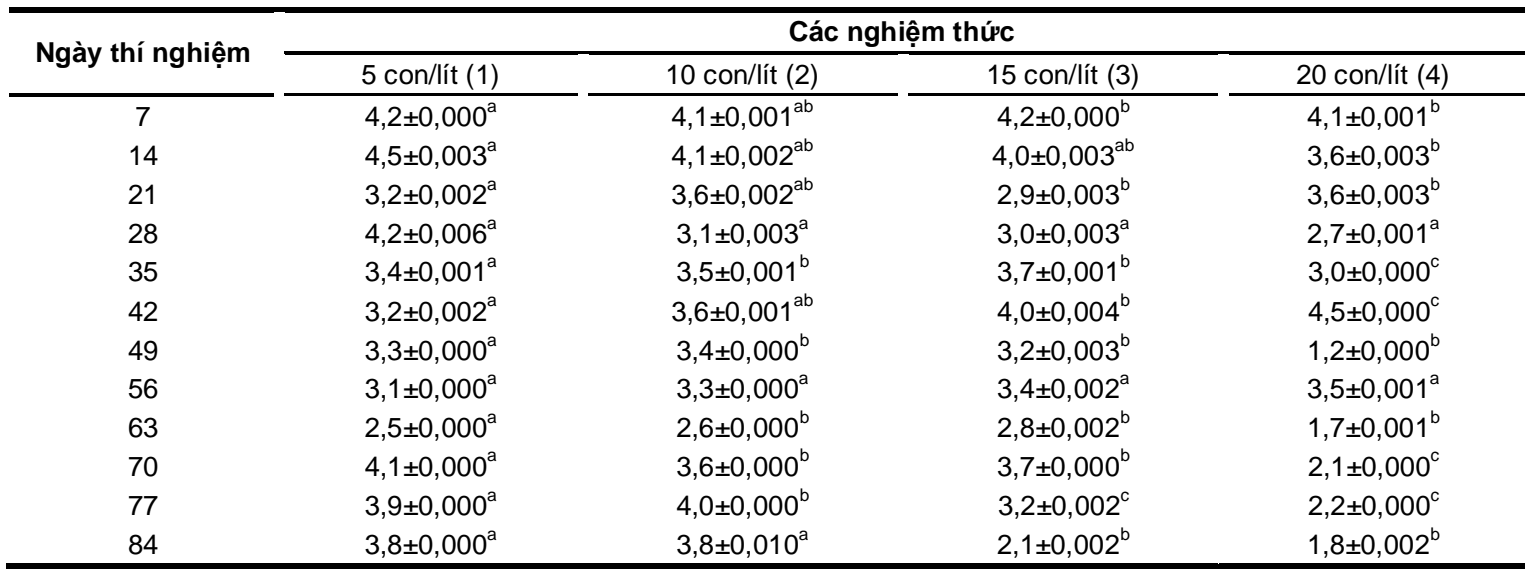




\section{Ảnh hưởng của mật độ nuôi đến tỷ lệ sống của cá ông tiên}

Trong 35 ngày đầu tiên, tỷ lệ sống ở các nghiệm thức không có sự sai khác $(\mathrm{p}>0,05)$ trừ nghiêm thức 1 . Từ ngày thứ 35 đến ngày 84 , nghiệm thức 1 và 2 có sự khác biệt với các nghiệm thức 3 và $4(p<0,05)$. Có thể thấy, trong thời gian 35 ngày đầu, tỷ lệ sống của cá trong tất cả các nghiệm thức đều giảm mạnh, do giai đoạn này các cá thể còn yếu, sau ngày nuôi thứ 42, các cá thể đã ở giai đoạn tiền trưởng thành, khả năng đề kháng tốt hơn nên tỷ lệ sống giảm ít hơn. Từ ngày 56 đến ngày 70 , cá bị nhiễm bệnh trong các nghiệm thức nên tỷ lệ sống giảm nhanh, sau 77 ngày đến ngày 84 , tỷ lệ sống giảm ít và ổn định hơn.

Bảng 4. Tỷ lệ sống (\%) của cá ông tiên ở các nghiệm thức

\begin{tabular}{|c|c|c|c|c|}
\hline \multirow{2}{*}{$\begin{array}{l}\text { Ngày thí } \\
\text { nghiệm }\end{array}$} & \multicolumn{4}{|c|}{ Các nghiệm thức (\%) } \\
\hline & 5 con/lít (1) & 10 con/lít (2) & 15 con/lít (3) & 20 con/lít (4) \\
\hline 1 & $100,0 \pm 0,00$ & $100,0 \pm 0,00$ & $100,0 \pm 0,00$ & $100,0 \pm 0,00$ \\
\hline 14 & $97,0 \pm 0,00$ & $97,5 \pm 0,50$ & $97,11, \pm 0,96$ & $97,1 \pm 0,38$ \\
\hline 21 & $97,0 \pm 1,00$ & $95,5 \pm 0,50$ & $95,4 \pm 0,38$ & $94,8 \pm 0,38$ \\
\hline 42 & $93,0 \pm 1,00$ & $90,0 \pm 0,50$ & $91,4 \pm 0,19$ & $88,4 \pm 0,57$ \\
\hline 49 & $91,0 \pm 1,00$ & $89,0 \pm 0,50$ & $89,2 \pm 0,19$ & $86,8 \pm 0,43$ \\
\hline 56 & $88,7 \pm 0,57$ & $87,0 \pm 0,50$ & $88,7 \pm 0,57$ & $84,8 \pm 0,43$ \\
\hline 63 & $84,7 \pm 0,52$ & $83,0 \pm 0,50$ & $83,1 \pm 0,38$ & $80,8 \pm 0,72$ \\
\hline
\end{tabular}

Ghi chú: Các giá trị trên cùng 1 hàng có các chũ cái giống nhau biểu thị sụ khác biệt không có ý nghĩa thống kê $(P>0,05)$.

Như vậy mật độ nuôi ảnh hưởng rất lớn đến tỷ lệ sống. Mật độ càng cao thì tỷ sống càng thấp. Sau 84 ngày nuôi, tỷ lệ sống ở nghiệm thức 1 là $85,0 \pm 1,00$, nghiệm thức 2 là $80,0 \pm 0,50$, nghiệm thức 3 giảm xuống còn $77,0 \pm 0,57$, nghiệm thức 4 chỉ còn $74,6 \pm 0,38$ tương tự các kết quả nghiên cứu trên đối tượng cá nemo con [1]. Theo Patrick Lavens \& Patrick Sorgeloos [5], mỗi mật độ nuôi có khả năng chống đỡ tối đa của mình, nếu cao hơn các mật độ này thì các điều kiện nuôi sẽ ở dưới điểm cực thuận (chất lượng nước kém đi, lượng thức ăn cho từng cá thể thấp hơn) tỷ lệ sống sẽ giảm đi, kết quả trong quá trình thí nghiệm cũng cho thấy điều này.

Từ kết quả thí nghiệm cho thấy mật độ nuôi thích hợp cho cá ông tiên giai đoạn mới nở đến 3 tháng tuổi có thể tiến hành theo thời gian như sau: từ 1 ngày tuổi đến 35 ngày tuổi có thể nuôi ở mật độ dầy đến 20 con/lít và từ 35-84 ngày tuổi có thể san thưa ương nuôi với mật độ 5-10 con/lít là thích hợp nhất. Đây là phương án nuôi có hiệu quả kinh tế cao hơn. Tuy nhiên nếu ương nuôi liên tục cung mật độ không san thưa thì mật độ ương nuôi 5 con/lít là tốt nhất, vừa đảm bảo tốc độ tăng trưởng và đạt tỷ lệ sống cao nhất so với các mật độ nuôi 10 con/lít, 15 con/lít và 20 con/lít có tỷ lệ sống thấp.

\section{KẾT LUẬN}

Mật độ nuôi có ảnh hưởng đến tăng trưởng và tỷ lệ sống của cá ông tiên giai đoạn 3 tháng đầu.

Cá được nuôi ở mật độ 5 con/lít có tốc độ tăng trưởng về chiều dài và trọng lượng $(9,597 \pm 0,002 \mathrm{~mm} ; 11,700 \pm 0,1 \mathrm{~g})$ là tốt nhất và khác nhau đáng kể so với cá được nuôi ở mật độ 10 con/lít $(9,167 \pm 0,058 \mathrm{~mm} ; 11,067 \pm$ $0,208 \mathrm{~g}) 15 \mathrm{con} / \mathrm{lít}(7,699 \pm 0,030 \mathrm{~mm} ; 10,933 \pm$ $0,057 \mathrm{~g})$ và 20 con/lít $(4,928 \pm 0,004 \mathrm{~mm}$; $7,900 \pm 0,100 \mathrm{~g})(\mathrm{P}<0,05)$.

Tỷ lệ sống của cá nuôi ở mật độ 5 con/lít là $85 \%$ cao nhất so với các mật độ còn lại 
(10 con/lít: $80,0 \pm 0,50 \% ; \quad 15$ con/lít: $77,0 \pm 0,57 \%$ và 20 con/lít: $74,6 \pm 0,38 \%$ ).

Phương án ương nuôi hiệu quả kinh tế cao tiến hành ương nuôi mật độ dầy khi cá con nhỏ sau san thưa như: cá từ $1-35$ ngày tuổi ương nuôi có thể đến mật độ 20 con/lít và cá từ 35-84 ngày tuổi ương nuôi mật độ 5-10 con/lít.

Do vậy, mật độ nuôi 5 con/lít là tốt nhất cho cá giai đoạn mới nở cho đến khi đạt 3 tháng tuối.

\section{TÀI LIỆ THAM KHẢO}

1. Nguyễn Trung Kiên, Thái Quốc Đại, Hà Lê Thị Lộc, 2010. Ảnh hưởng của mật độ nuôi lên tốc độ tăng trưởng và tỷ lệ sống cá Khoang cổ nemo Amphiprion ocellaris Cuvier 1830. Tạp chí Khoa học và Công nghệ. Hội nghị các nhà khoa học trẻ trong lĩnh vực Khoa học Tự nhiên và Công nghệ. Tập 48. Số 2A. Tr. 655-660.

2. Trương Quốc Phú, 2006. Quản lý chất lượng nước nuôi trồng thủy sản. Giáo trình Cao học Nuôi trồng. Đại học Cần Thơ. 300 tr.

3. Võ Văn Chí, 1993. Cá cảnh. Nxb. Khoa học và Kỹ thuật.

4. Froese R., and D., Pauly, 2000. The CDRom Version of Fishbase. Four disks. ICLARM. Philippines.

5. Patrick Sorgeloos and Patrick Lavens, 1996. Manual on the production and use of live food for aquaculture.

6. http://en.wikipedia.org/wiki/Pterophyllum

7. http://www.amazon.com/FreshwaterAngel-Fishes-Herbert-Axelrod/dp/0866227652

\title{
EFFECT OF STOCKING DENSITY ON GROWTH PERFORMANCE AND SURVIVAL RATE OF ANGEL FISH (PTEROPHYLLUM ALTUM PELLEGRIN, 1930)
}

\author{
Ha Le Thi Loc ${ }^{1}$, Nguyen Thi My Dung ${ }^{2}$ \\ ${ }^{1}$ Institute of Oceanography-VAST \\ ${ }^{2}$ Nha Trang University
}

\begin{abstract}
Three-day-old Angel fishes (Pterophyllum altum) were utilized to investigate the effect of stocking density on their growth performance and survival rate. The fish were cultured in 25 liter, glass tanks at different treatments of density, including 5 individuals $/ L, 10$ inds $/ L$, $15 \mathrm{inds} / L$ and $20 \mathrm{inds} / L$ (triplicated). The results after 84 days showed that growth and survival rate of angel fish were significantly influenced by stocking density. The length and weight of fish reared at 5 inds $/ L(9.597 \pm 0.002 \mathrm{~mm} ; 11.700 \pm 0.1 \mathrm{~g})$ were the best and significantly higher than fish in the treatment of $10 \mathrm{inds} / \mathrm{L}(9.167 \pm 0.058 \mathrm{~mm} ; 11.067 \pm 0.208 \mathrm{~g}) ; 15 \mathrm{inds} / \mathrm{L}(7,699 \pm 0,03 \mathrm{~mm} ; 10.933 \pm$ $0,057 \mathrm{~g})$ and $20 \mathrm{inds} / \mathrm{L}(4.928 \pm 0.004 \mathrm{~mm} ; 7.900 \pm 0.1 \mathrm{~g})(P<0.05)$. The survival rate of 5 inds $/ \mathrm{L}$ treatment $85 \%$ was significantly higher than that of other treatments (10 inds/L: $80.0 \pm 0,5 \% ; 15$ inds/L: $77.0 \pm 0,57 \%$ and 20 inds/L: $74.6 \pm 0.38 \%$ ). In combination of these two factors, the density of $5 \mathrm{inds} / \mathrm{L}$ is recommended in culture of three day old to three month old angel fishes.
\end{abstract}

Key word: Stocking density, growth, survival rate. 